\title{
Implications of Risk Governance in Genetically Modified Food: A Comparative Discussion on European and United States Contexts
}

\author{
A B M Enamol Hassan ${ }^{1} \&$ Nazma Afroz ${ }^{2}$ \\ ${ }^{1}$ Department of Humanities (Sociology), Chittagong University of Engineering and Technology, Chittagong, \\ Bangladesh \\ ${ }^{2}$ Department of Humanities (Economics), Chittagong University of Engineering and Technology, Chittagong, \\ Bangladesh
}

Correspondence: A B M Enamol Hassan, Department of Humanities, Chittagong University of Engineering and Technology, Chittagong-4349, Bangladesh. Tel: 880-1913-010187. E-mail: enamsoc@cuet.ac.bd

Received: May 17, $2020 \quad$ Accepted: June 9, $2020 \quad$ Online Published: July 22, 2020

doi:10.5539/ass.v16n8p33 URL: https://doi.org/10.5539/ass.v16n8p33

\begin{abstract}
The rapid growth of world population has increased the demand for Genetically Modified Food (GMF) to fulfill the global nutritional needs. Simultaneously, it also needs to understand the cross-national contexts based on the risk governance of this newly emergence of food technologies. Thus, the paper tries to exhibit a comparison on GMF between United States (US) and European Union (EU) using the risk governance framework. Hence, the study uses the risk governance framework as a model that incorporates risk assessment, concern assessment, risk characterization and evaluation, risk management, and risk communication. The paper is based on secondary source of data collection and the two areas (US and EU) is purposively selected for this comparative discussion. The result shows recent controversies on usage of GMF between US and EU highlighting the apparent differences that does exist in all spheres of risk governance.
\end{abstract}

Keywords: genetically modified food, risk perception, trust, risk management, public concern, acceptability

\section{Introduction}

The rapid growth of human population increases the demand for new forms of food to meet the needs of nutrition and for keeping good immunity power in human body. In this case, Genetically Modified Organism (GMO) could be a good source of fulfilling the demand for food, as this new bio-technology emerged new form of food like Genetically Modified (GM) food (Tenbült, 2005). GM food could be referred as the product whose genetic material is derived and modified from different organismic gene rather than naturally occurred (Pechan et al., 2011). In fact, Genetically Modified (GM) crops were introduced to control pests and weeds to reduce viral damage to crops. The adoption of GM food has evolved over time to include the improvement of both quality and taste with regards to nutrition, health, and removing allergens (Pechan et al., 2011). However, it is now increasing concerns about the benefits and possible risks of GMF to human health and safety and also to the environmental sustainability (Pechan et al., 2011). A central reason is that the proponents of GMO technology, such as government agencies, companies, researchers were no adequately communicated with each other at an early stage. They were also not communicated with mass people about the safety of the technology and the benefits that it brings to society (Teng, n. d.). The challenges with the use of GMF are the uncertainty surrounded with its impacts on both the human health and the environment (Pechan et al., 2011), as well as the lack of insufficient scientific knowledge to make relevant judgments (Tait, 2008). On the other hand, global trade, economy, emergence of new biotechnology and international governance increase the human demand for safe and quality food. Thus, cross-cultural nations always try to make a comprehensible sense about implicated risk factors of GMF that is the outcome of newly emerged biotechnology (Finucane \& Holup, 2005). Different nations may address the risks and benefits of GMF differently and the cross-cultural differences are likely to create group conflict when they come to reconcile the complex array of health, environment, and social benefits of GMF.

Hence, The paper focuses on carrying out a descriptive analysis on GMF in both EU and USA; using the integrated framework of risk governance. It follows one overarching research question in describing the research objective: Why the people in the US seemingly untroubled with risk governance on GMF that causes Europeans 
so many difficulties. In addition, the authors explored the answer of this research question on the basis descriptive insights, so the paper is based on descriptive in nature.

\section{Method}

The paper is based on secondary source of data collection, so the data and information were collected from existing literatures. The authors searched the electronics databases such as Google Scholar, ProQuest Central, and Science-Direct to identify the relevant studies published recently in English. The research sights (US and European Union) are purposively selected for making comparison, as these two area are different on perception and usage of GMF.

\section{Results and Discussion}

\subsection{Risk Assessment}

Environmental Protection Agency of US's demonstration about risk assessment is noteworthy indeed, as risk assessment is evaluating procedure about how likely the environment could be effected by the result of exposure with environmental stressors e.g. use of pesticides, processed and manufactured food, disease, land change, and invasive species (US EPA, n. d.). They can be used to study those substances that are intentionally added to food (such as processing aids, food additives, veterinary chemicals, or agricultural) along with those substances that occur accidentally in food like pathogenic microorganisms, environmental contaminants, or naturally-occurring toxins, as well as the effect of new bio-technologies. For the most part, risk assessment goes through three distinct processes: the identification and estimation of hazard: understanding adverse effects and assessing cause-effect links, the assessment of exposure and vulnerability: modeling of diffusion, exposure and effects on risk targets, estimation of risk: combining likelihood and severity of consequences based on exposure/vulnerability assessment (US EPA, n. d.). The Food and Drug Administration (FDA) has a key responsibility for ensuring the food safety in US and also hold a position of take legal action against the food's manufacturer in case of demonstrating safety risk during the post-market (Kuzma \& Haase, 2012). Risk assessments use information that is already available on the health consequences and exposure of GMF. There have been arguments that the consumption of GMF has been used and consumed for two decades without any health effects and also that there is no valid reason for them to be singled out when it comes to more regulatory inspection than traditional bred food (Kuzma \& Haase, 2012). The European's take on GMF have to go through the process of requesting the use of a particular GM crop, along with this, the markets approval must be submitted to the proper Member State and/or the European Commission (EFAS, n. d.). The GM application for placing GM products on the market follows these several procedures: the member states are categorized as first notified countries to GMO application for carrying out risk assessment. The Member State's risk assessment report is required to send to the European Commission (EC), and then EC forwards the report to all member states for their evaluation and comments regarding risk assessment. If any member states raise objections and the EC fails to resolve the dispute, European Food Safety Authority (EFSA) is asked to provide an opinion (within 90 days) especially focusing on the points of scientific divergence between the Member States. The task is then placed on the EFSA- GMO panel to carry out the risk assessment needed. This panel is made up of twenty-one independent experts, whose job is to look into how safe the GM product is by using the data that the applicant provided; additional scientific data and information should be available through additional sources such as scientific literatures or research projects and their own expertise and knowledge of the subject (EFAS, n. d.).

\subsection{Concern Assessment}

Concern assessment, as a part of interdisciplinary risk estimation (Klinke \& Renn, 2012), includes public concerns with social scientific implications about a certain risk.

In assessing the concern of two different continents (EU and US) about GMF, it is found different scenarios. In Europe, a significant portion of population would like to avoid GMF (Baur \& Gaskell, 2002 ; Gaskell, 2005; Perrez et al., 2003) those are mostly inclined to retain their right to choose food expecting clear indication about whether it is health hazard or not (Claessens, 2002). On the other hand, a negligible number of people are concerned about the quality of the GMF in US. Although opponents of technology showing opinion in against of GMF but still they are not dominant in raising mass awareness (Martin \& Trait, 1992). Golden Rice, for instance, they think that it is a food that could save millions from Vitamin A deficiency. Producing foods through biotechnology could produce significantly health benefits, especially for the poor in developing countries (Smith, 2006). On the other hand, Claessens (2002) reveals that European people want to retain the right to choose between natural food and GM food which means that European public expects clear indication of GMO-basis on the packaging of food in supermarket or in menus of restaurants. Eighty percent of all teen agers and adults in the 13 countries await more information before consuming GMF about whether it is health hazard or not. 
Gaskell et al. (2000) revealed the different views that Europeans had no knowledge or understanding about GMF until 1996 and a large proportion of population answered "Don't Know" to the questions about biotechnological application. Aftermath, their perception about GMO is likely to develop in 1999, as $80 \%$ respondents were inadequately informed about biotechnology. Smith (2006) focused on two consumers' survey of 1997 and 2005 in US and EU, which reveals very negligible change in US consumer perceptions on biotechnologically produced food, as in 2001, 74\% people did not think about the necessity of food labels, which increased by $76 \%$ in 2005. Further, $78 \%$ of people feel that biotechnology would provide benefit for family and in 2005 that just declined to $10 \%$. In perspective of Europe, Smith focused on Euro barometer report, published in 2006, that reveals $42 \%$ of people think the food they eat is damaging their health and the same proportion also believes that consumer goods are likely to damage their health expressing worried about the products of technology. As shown in below figures $(01,02)$ -

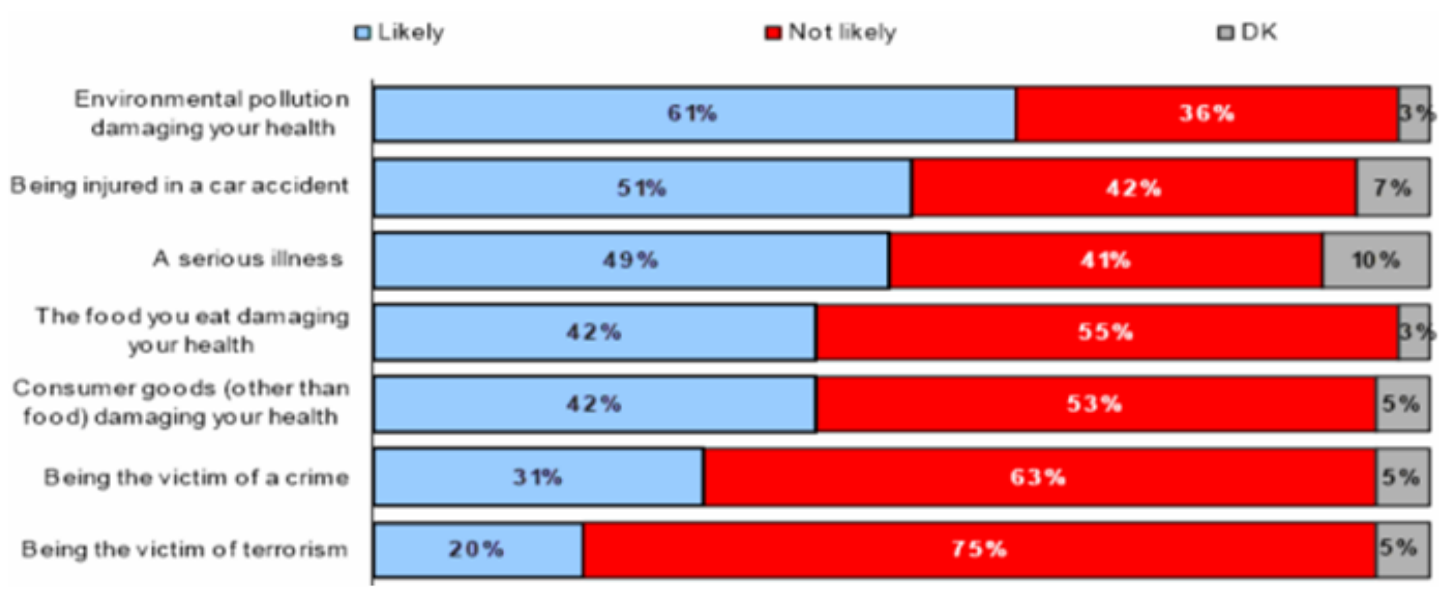

Figure 1. Respondents' perception about the rate of damage happening in life

- Very worried $\square$ Fairly worried $\square$ Not very worried $\mathbf{U}$ Not at all worried $\square \mathrm{DK}$

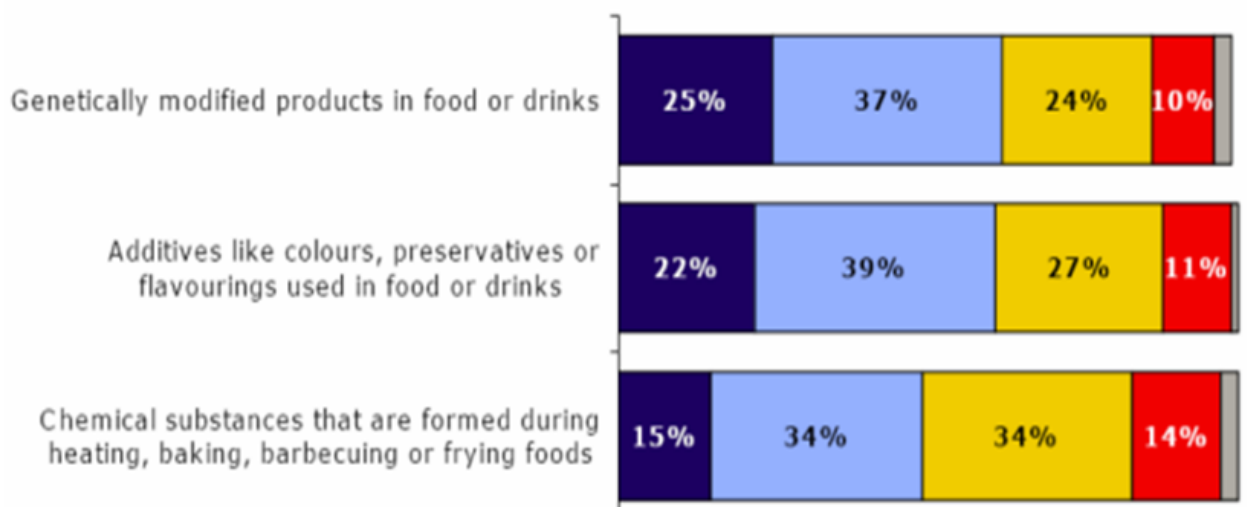

Figure 2. Respondents' perception about how they are likely to worry

Marco (2010) depicted European people's concern about the four technologies showing a significant proportion of consumers surveyed expressing moral reservation about GM food and the belief that they are risky. As in below figures $(03,04)$ - 


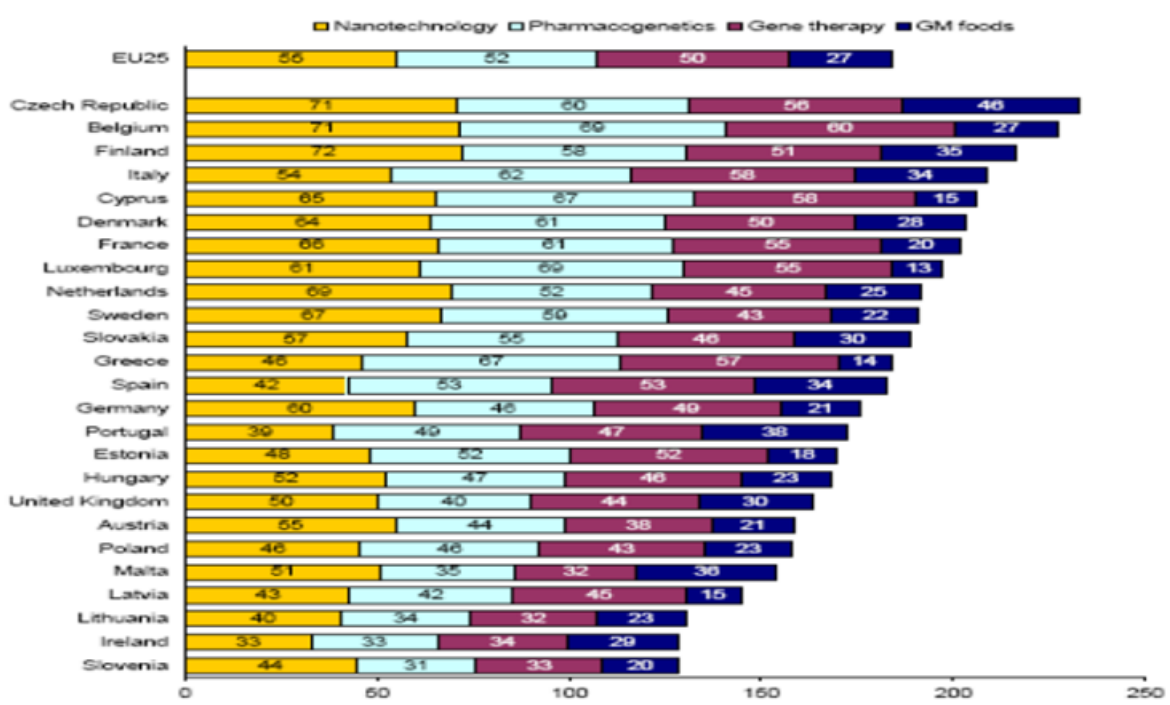

Figure 3. Public support for four different technologies in EU

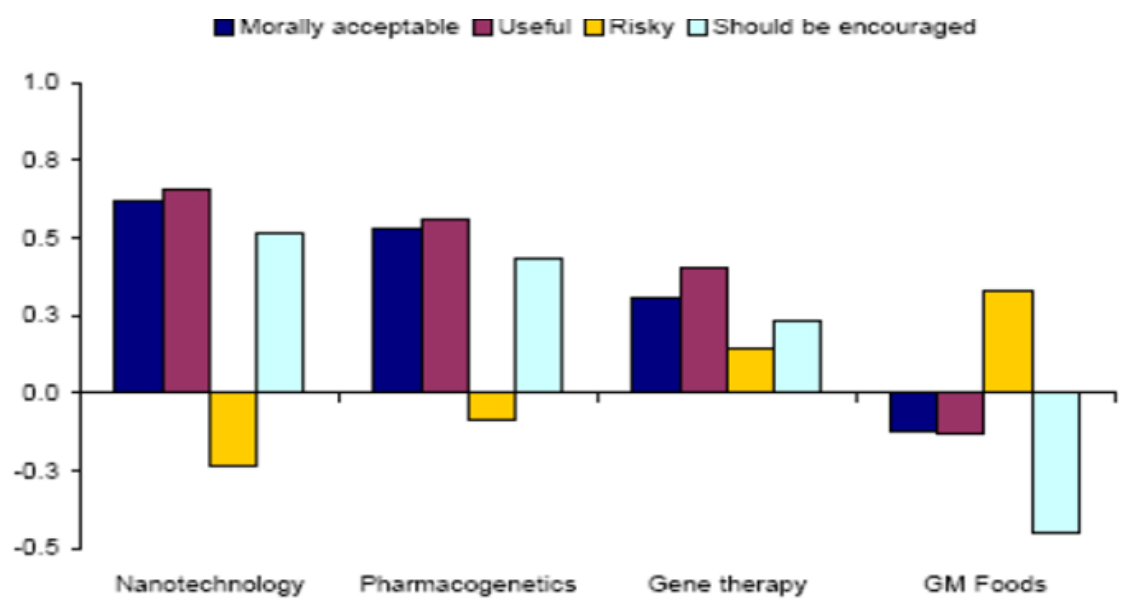

Figure 4. Public evaluation for four technologies in EU

Actually, the socio-economic factors (Timar, n. d.) influence consumer views on genetically modified foods. In Europe, regulatory activities are very strong (Curtis et al., 2004) and media coverage fully goes to the favor of consumers (Tait, 2008). Moreover, an integrative legal body regulates the production and the sale of GMF by enhancing the effectiveness of the EU food safety system, which is undermined in US. European press also works in favor of public sentiment by composing that there are no public benefits from GM products (Tait, 2008). A significant increase in media coverage of the effects of biotechnology influenced in Western and Northern Europe strongly to protest the arrival shipments of "Monsanto GM Soybeans" in 1996 (Bauer et al., 2001; Grabner et al., 2001). In addition, media also represented the effects of biotechnology under the discourse of "risk-oriented vs. benefit-oriented" (Bauer et al., 2001). A study of Hoban (1997) exhibited a finding of Food Market Institute survey carried out in 1995-1996 and found that US consumers were also less aware of the effects of biotechnology. The trans-Atlantic debate is noteworthy at this point, as there is a great difference in public opinion between the US and European countries. Such as American people embraced GM foods, whereas European countries had just permissive regarding GM production rather than mass consumption (Losey, Rayor \& Carter, 1999). Aftermath, European concerns were dramatically increased through multiple food scandals such as mad cow disease which contributed to widespread distrust of GMF (Finucane \& Holup, 2005). In 1995, The Food Market Institute survey exhibited the findings that thirty three to fifty percent of European respondents viewed the risk of FMF as a serious health hazard, whereas only twenty percent of US respondents viewed the GMF as health hazard (Hoban, 1997). Similarly, the survey in 1997 revealed that 30\% European respondents (only 13\% of US citizen) opposed the GMF (Gaskell et al., 1999). Therefore, it is noteworthy that the 
distinguishing public assessment on GMF is an ultimate representation of risk management as a whole, which are currently being practiced in two continents with different views and actions.

\subsection{Risk Characterization and Evaluation}

The interdependencies and uncertainties surrounding GM crops and foods make it difficult for scientists to clearly explain many of its potential risks. This uncertainty makes scientific arguments weak and gives weight to varied public opinions (Pechan, 2011). The above led to its regulation based on scientific extrapolation rather than scientific evidence in US (Tait, 2008). The US approach to regulating GM crops is reactive as threats are only attended after its occurrence and measures put in place to prevent reoccurrence in the future. The US adopts the product-based system, which regulates GM products through the existing regulatory system for pesticides and foods depending on the product characteristics. (Tait, 2001). Substantial equivalence is adopted and GMF are compared to similar foodstuff in the market and if there are no major differences, they are assumed the same and therefore not requiring further regulations (Tait, 2008). The European countries, on the other hand, recognizes the limitations of science in situations of uncertainty as it pertains to green biotechnology (Levidow, 2001). Thereby, it adopts the process-based approach founded on the precautionary principle, which would subject the GM products to distinct regulatory examination, as it is originated from new technology. The adoption of the precautionary approach to GMF regulation in European countries is a response to the perceived failures in the reactive regulatory system for pesticides (Tait, 2001). The European countries are cautious, as they justify the adoption of the precautionary approach on grounds of uncertainty about the possible impacts of GM products on the health and environment (Tait, 2001). They also regard public concerns and probable risks without solid evidence to suggest hazard. Substantial equivalence is disapproved and some writers have recommended the application of methods used on drug testing to GMF (Millstone et al., 1999).

There is greater public support for GM foods in US than EU (Gaskell et al., 1999). Thus, US with higher public acceptance of GM foods have established its benefit in the management and efficacy of food production through prevalent use by farmers, which is benefit for both the agricultural industry and the public (James, 2002; Bennet et al., 2006). The absence of risks or unacceptable level of risks and public costs seems to be enough justification for the acceptance of the technology in societies that have supported and introduced GM foods (Tait, 2008). The $\mathrm{EU}$, on the other hand, focused on the public concern about potential consequences of adopting the biotechnology (Tait, 2008) with recent analysis of attitudes to GMOs carried out in 2006 in Germany showing more positivity in its use outside of the "green" area. The public does not see obvious benefits of GM products over and above organically grown crops (Pechan, 2011).

In fact, when it comes to GM products, product acceptability or tolerability is more pertinent than risk acceptability or tolerability. This is because there is a scientific uncertainty surrounding potential risks associated with GM products and not enough risk information to support adverse reaction of the public to the development and adoption of GM foods (Tait, 2008). In EU and US, there is a large minority of the populace that finds GM foods inherently unacceptable irrespective of risks and benefits attached to its use (Tait, 2008). The difference is the EU gives much credence to the concerns of this minority and tailors the risk governance process around their apprehensions while the US risk governance process on the other hand is less influenced by the opposition from this minority (Tait, 2008). In both the US and EU, the greater percentage of the population are indifferent about the sources of food, if it is from GMO or conventional crop variations (Tait, 2008). Gaskell et al. (1999) carried out a survey that revealed the same finding, as the majority of people in both US and EU are indifferent about the source of their food.

\subsection{Risk Management}

Risk management is the process of reducing risks to a level deemed acceptable by society and to ensure that control, monitoring and public communication is covered (Zimmerman, 1986).

The approach to managing GM foods in Europe, both at the national level and in the European Union stands in marked contrast to that of the US. The EU first became involved in GMOs regulation in the mid-1980s and has in place a comprehensive legal framework for authorization, traceability and labeling of GM foods (EC, 2000). On the other hand, regulation in the US has been in effect since 1986, and it regulates GMOs according to their characteristics and unique feature. However, US did not form any uniformed production method, which means that there is no distinct regulatory strategic authority in the USA to evaluate GM products that subject to approval. Thus, the responsibility goes to the existing agencies to oversee the safety of GM products including foods (US FDA, 2003). These self-reliant agencies are the Food and Drug Administration (FDA), the Environmental Protection Agency (EPA), and the United States Department for Agriculture (USDA), and they have shared responsibility for regulating and promoting the introduction of GMOs in the United States. "Sound 
science" approach is used by these agencies to regulate risk (US EPA, 1997). There are two features of characterizing this particular task of risk management that could be accomplished. Firstly, administrative strategies must consider the assigned and relevant regulation that is taken into account to justify in the form of scientific base, policy rationale, and legal authority. Secondly, US regulatory board takes the decision that must be opened for legal review in order to lead for litigation (US EPA, 1997). The difference between the US and EU regulatory policies are striking, in that the European Food Safety Agency (EFSA) and its member states are responsible for regulating GMO using a process-oriented approach which adopts the precautionary principles as the main strategic mechanism for evaluating risk management (EC, 2000). To follow the environmental legislation, originated in German in 1960s, cautious approach is emphasized as the precautionary principle in adopting the new technology, if the existing scientific understanding is not complete and even no consensus comes in regards to the nature of threat. In maintaining the precautionary principle, the burden of proof has been shifted to the technology and its developers with a view to demonstrate the protection of a new technology (Becker, 2006). In addition, The EU approval system is not only followed by scientific evidences but also based on significant scope of other nonscientific factors in regards to the risk management decisions. In consequence of this cautionary approach, there are significantly few numbers of GM foods that is available in whole Europe (Young, 2007). In addition, the EU is likely to ensure the greater right of access to the information of their consumers than the people of the US. Consequently, there are much strict rules in the EU on traceability and labeling of GM products that are subject to enforce the producer to maintain in production and marketing since the inception of 2001 legislation (Young, 2007). Although labeling and traceability are mandatory to be sealed in all approved GM products in EU, it does not apply to GM products in a proportion no higher than 0.9 percent of the food considered individually. In addition, the presence of labeling is adventitious and technically unavoidable, whilst these labeling requirements are voluntary in US. US require labeling only the products, which differ from their non-genetically modified counterparts (Gaskell et al., 2006). Nearly three-quarters of all genetically modified foods come from the United States and hardly any from Europe (USDA, 2006). Large differences persist in European (45\%) and US (61\%) public perceptions about the safety of GM foods and the competence of their food safety regulators (Gaskell et al., 2006). Consumer preference is strong in EU and weak in the US. As a result, public opinion in EU was extremely skeptical about governance assurances concerning the safety of GMO technology and continues to be so to this day (Becker, 2006). Trans-Atlantic differences over GM foods are the features of varied and distinguished institutional approaches to risk management. The EU, to follow the precautionary principle, argues that responsibility in ensuring the measure of safety of GM products definitely lies to the producers and simultaneously consumers' demands for accountability, transparency and right of access to information must be considered (Young, 2003). On the other hand, the US has reasoned that the absence of scientific indication and evidence in case, every GM product could be treated likely the same way and has relinquished the labeling and traceability requirements (USDA, 2006).

\subsection{Risk Communication}

Risk Communication is the process of communicating responsibly and effectively about the risk factors associated with industrial technologies, natural hazards, and human activities (Powell \& Leiss, 1997). Risk communication is closely related to other phases of the risk governance. It involves actors of different fields such as researchers, companies, policy-makers, environmental groups (e.g. NGO), and the public. Coordination with national food safety and regulatory authorities needs risk communication. Scientists or experts from the GM product industry are responsible for providing scientific evidence to the public. Public opinions, attitudes and perception are the significant factors in determining the market of the food supply of biotech products. (Teng, n.d.). Slovic (1987) stated that risk communication and risk management efforts would fail unless they structured as a mutual process between public and experts. Different stakeholders adopt different fields to cope with various challenges and essential communication skills are needed for numerous situations in both European countries and US. Risk communication is, therefore, recognized tool for effective communication on complex subjects such as the controversial and uncertain issues about GMF in both cases. The different reactions of European and American public can be explained by the theory of risk perception, influenced by communication strategies. European perception of GMF is "better safe than sorry", while the American perception is "indifferent" according to Risk Matrix proposed by Margolis (Margolis, 1996). The advocacy coalition, involving groups with environmental, third world and consumer-related agendas dominated the media presentation and the framing of the GMF debate and provided an example of very successful, integrated communication strategy that enabled this coalition to dominate the agenda in Europe. Mad Cow disease and dioxin in food supply chains aroused the widespread public attention on the food safety issues in Europe. European consumers, therefore, cared much more about information about genetic modified products as alternatives for traditional food products (Carl, 2001) that certain stakeholders are trusted and others viewed as skeptical in Europe (Priest \& Bonfadelli, 2003; 
Poortinga \& Pidgeon, 2003; Gaskell \& Allum et al., 2003) due to the conservative nature of communication adopted by various actors. The effects of trust as a prerequisite for risk communication about technologies as GMF are explored by many researchers in the USA (Poortinga \& Pidgeon, 2003; Siegrist, 2000). Given the scientifically complex opinions on GMF, relying on the information presented by trusted social actors provides the public an opportunity to resolve doubt (Lang \& Hallman, 2005). In the case of US, Hoban found that $62 \%$ of survey respondents had not heard of "bovine somatotropin" when it was first introduced in US (Hoban, 1994). This shows that US consumers were not aware of the potential danger of GMF, because the appearance of the food is the same as the traditional products in the market. In addition, the actors including companies and agencies presented as a new technology just like any other agricultural innovation. In this case, the communication strategies adopted by main actors created trust, which played a major role in the US public views on GMF as well (Freudenberg, 1993). Communication of GM risk has been influential in management decisions in both EU and USA. Due to spreading information from media and interest groups, the terrible facts about unqualified food supply also contributed to the establishment of new European food safety authority by European Commission which believed that the action on food safety is of great significance to regain the confidence of the consumers (Smith, 2000) through producing trusted evaluations of food safety. As to the regulations, the exposure to disasters and danger on GMF makes the consumers able to see the dangerous side of GMF, and policy makers in Europe are responding to the caution of consumers on the community by adopting policies and practices that emphasize safety (Grossman \& Endres, 2000). This led to the application of a precautionary principle of managing GMOs in the area. Hence, these products are kept out of market until they prove safe for human consumption.

In Contrast, industry and public action groups are trying to influence the direction of US management through advertising and other forms of communication (Lang \& Hallman, 2005). The regulation of biotechnology food products does not differ fundamentally from regulation of conventional food products due to the way of communication presenting them to the market. Using a multiagency approach, therefore, to communicate information about partial evaluations of genetically altered crops and influenced management of GMOs under the principle of leaving commodities in market until proven harmful (Vogt, 1999). This explains why there are many GMO products in the USA market, with very little consumer oppositions. Generally, Tait (2008) pointed out that it was apparent that the failure of communication risen among different stakeholders from the perspectives of EU and US. The problems are that the policy makers fail to explain the reasons to regulate the appropriate policies to the public and prioritize the economic benefits. What is more, companies are affected when they lack the liaison of other sectors as in the case of GMOs in both cases. Risk communication enables sharing of insights into aspects of the risks that might not have been considered, other concerns and strategies for risk management (Teng, n. d.), appropriate communication is therefore essential for all leaders, policy makers, managers or researchers.

\section{Conclusion}

The essence of democracy in the governance process relies on making just decisions free from influence by dominant interests' groups. The huge influence of advocacy groups regarding the GM crops in EU according to many exemplifies powerful interest dominating the regulatory outcome. Another perspective to the regulatory approach in EU is the substitution of the interest of one organized group (the agro-biotechnology industry) with another, more powerful (advocacy groups). The result is negative for democratic decision-making on risk matters (Tait, 2008 p.146). In the last few decades, GMOs have been commercially adopted by North America, but are to be adopted by some countries in Europe. Such countries in the EU have adopted more stringent regulations such as requiring mandatory labeling of such crops (Gostek, 2016). Eventually, GMF regulations in EU may negatively impact its economy by restricting the growth of the GM crop industry. For better understanding and analyzing of risk assessment about genetically modified crops, it is widely accepted now to input the risk governance framework which could usefully be developed further to improve its future applicability to the development of new technologies in a globally scale which challenges the capacities of existing regulatory systems (Tait, 2008, p.147).

\section{References}

Alasdair R. Y. (2003). Political Transfer and 'Trading Up'? Transatlantic Trade in Genetically Modified Food and US politics. World Politics, 55. https://doi.org/10.1353/wp.2003.0026

Bauer, M. W., \& Gaskell, G. (2002). Biotechnology: The making of a Global Controversy, Cambridge University Press, cited by Tait, J. (Eds.). (2008). Risk Governance of Genetically Modified Crops: European and American Perspectives. In O. Renn, \& K., D. Walker (Eds.), Global Risk Governance: Concept and 
practices Using the IRGC Framework. Springer, The Netherland.

Bennett, R., Morse, S., \& Ismail, Y. (2006). The economic impact of genetically modified cotton on South African small holders: Yield, profit, and health effects. Journal of Development Studies, 42(4), 662-677. https://doi.org/10.1080/00220380600682215

Carl, H. N. (2001). Risk perception, behaviour and consumer response to Genetically Modified Organisms: toward understanding American and European public reaction. American behavioural scientist, 44(8), 1371-1388. https://doi.org/10.1177/00027640121956737

Claessens, M. (2002). Public Perception of Science in Eastern and Central Europe. Retrieved from www.upf.edu/pcstacademy/_docs/236_Claessens.pdf

Curtis, K. R. et al. (2004). Consumer Acceptance of Genetically Modified Food Products in Developing Country. AgBioForum, 7(1\&2), 70-75.

Daniell, H. (2002). Molecular Strategies for gene containment in transgenic crops. Nature Biotechnology, 20, 581-586. https://doi.org/10.1038/nbt0602-581

Department of Health and Human Services, Food and Drug Administration. (2001). Pre-market notice concerning bioengineered foods. Proposed Rule. 66 Fed. Reg. 4706 (January 18, 2001).

Environmental Protection Agency. (1997). Microbial products of biotechnology; Final, Regulation under the Toxic Substances Control Act (Final Rule). 70 Fed. Reg. 17910, April 11, 1997.

European Commission. (2000). The applicability of the precautionary principle. Communication Paper COM (2000) 1. Brussels: European Commission.

Finucane, M. L., \& Holup, J. (2005). Psychological and cultural fctors affecting the perceived risk of genetically modified food: An overview of the literature. Social Science and Medicine, 60, 1603-1612. https://doi.org/10.1016/j.socscimed.2004.08.007

Freudenberg, W. R. (1993). Risk and recreancy: Weber, the division of labor, and the rationality of risk perceptions. Social Forces, 71(4), 909-932. https://doi.org/10.2307/2580124

Gaskell, G. (2005) Double eurobarometer survey: Citizens, science and technology. RTD Info-Special Eurobarometer Issue, November, 3-32; cited by Tait, J. (2008) Risk Governance of Genetically Modified Crops: European and American Perspectives. In O. Renn, \& K. D. Walker (Eds.), Global risk governance: Concept and practices using the IRGC Framework. Springer, The Netherland.

Gaskell, G., Allum, N. C., \& Stares, S. R. (2003). Europeans and biotechnology in 2002: Eurobarometer 58.0. Brussels, Belgium: European Commission.

Gaskell, G., Bauer, M. W., Durant, J., \& Allum, N. C. (1999). Worlds apart? The reception of genetically modified foods in Europe and the US. Science, 285, 384-387. https://doi.org/10.1126/science.285.5426.384

Geoffrey B. (2006, September 5). Agricultural biotechnology: Background and recent issues. CRS Report for Congress.

George, G., et al. (2006). Europeans and biotechnology in 2005: Patterns and trends. Eurobarometer, 3, 64.

Gostek K. (2016) Genetically modified organism: How did United States and European Union's Regulations Affect the Economy. Michigan State International Law Review, 24(3).

Grossman, M. R., \& Endres, A. B. (2000). Regulation in the genetically modified organisms in the European Union. American Behaviour Scientists, 44(3), 378-434. https://doi.org/10.1177/00027640021956260

Hoban, T. J. (1994). Consumer awareness and acceptance of bovine somatotropin. Washington, DC: Grocery Manufacturers of America.

ISO /IEC 31000. (2009). Risk Management - Risk Assessment Techniques.

ISO 31000. (2009). Risk Management- Principles and Guidelines on Implementation. Retrieved from www.en.wikipedia.org/wiki/ISO_31000

James, C. (2002). Global review of commercialized transgenic crops featuring Bt. Cotton. ISAAA Brief No. 26, International Service for the Acquisition of Agri-Biotech Applications, Ithaca, SÁ.

Klinke, A., \& Renn, O. (2002). A new approach to risk evaluation and management: Risk-based, precautions-based and discourse-based management. Risk Analysis, 22(6), 1071-1094. https://doi.org/10.1111/1539-6924.00274 
Klinke, A., \& Renn, O. (2012). Adaptive and integrative governance on risk and uncertainty. Journal of Risk Research, 15(3), 273-292. https://doi.org/10.1080/13669877.2011.636838

Kuzma, J., \& Haase, R. (2012). Safety assessment of genetically engineered foods: US policy and science. Retrieved from https://www.semanticscholar.org/paper/Safety-Assessment-of-Genetically-Engineered-Foods\%3 A-Kuzma-Haase/0a0eea5a2722cb6 $13 f 5467658677$ e4 fdb823b141

Lang, J. T., \& Hallman, W. K. (2005). Who does the public trust? The case of genetically modified food in the United States. Risk Analysis, 25, 1241-1252. https://doi.org/10.1111/j.1539-6924.2005.00668.x

Levidow, L. (2001). Precautionary uncertainty regulating GM crops in Europe. Social studies of science, 31(6), 842-874. https://doi.org/10.1177/030631201031006003

Marco, V. (2010). Consumer perception and GMOs in the European Union; Policy Responses to Societal Concerns in food and Agriculture; Proceedings of an OECD workshop. Retrieved from www.oecd.org/tad/agricultural-policies/46838061.pdf

Margolis, H. (1996). Dealing with risk: Why the public and experts disagree on environmental issues. Chicago: University of Chicago Press.

Millstone, E., Brunner, E., \& Meyer, S. (1999). Beyond 'substantial equivalence'. Nature, 401, 525-526. https://doi.org/10.1038/44006

Nickson, T. (2008). Planning environmental risk assessment for Genetically Modified Crops: Problem Formulation for Stress-Tolerant Crops. Plant Physiology, 147(2), 494-502. https://doi.org/10.1104/pp.108.118422

OECD. (1993). Safety evaluation of foods derived by modern biotechnology: Concepts and principles. OECD, Paris.

Pechan, P., Renn, O., Watt, A., \& Pongratz, I. (2011). Safe or not Safe. New York, NY: Springer, New York. https://doi.org/10.1007/978-1-4419-7868-4

Perrez, F. X., Christoph, E., \& Krisztina, B. (2003). GMO-regulation: Case study for Switzerland. Retrieved from www.law.nyu.edu/sites/default/files/upload_documents/ Switzerland_12-03.doc.

Poortinga, W., \& Pidgeon, N. (2003). Exploring the dimensionality of trust in risk regulation. Risk Analysis, 23(5), 961-972. https://doi.org/10.1111/1539-6924.00373

Powell, D., \& Leiss, W. (1997). Mad Cows and Mother's Milk: The Perils of Poor Risk Communication. McGill-Queen's University Press, Montreal.

Priest, S. H., Bonfadelli, H., \& Rusanen, M. (2003). The "trust gap" hypothesis: Predicting support for biotechnology across national cultures as a function of trust in actors. Risk Analysis, 23(4), 751-766. https://doi.org/10.1111/1539-6924.00353

Risk Assessment. (2016). Food standards.govt.nz. Retrieved from http://www.foodstandards.govt.nz/science/riskanalysis/riskassessment/Pages/Risk-assessment.aspx

Siegrist, M. (2000). The influence of trust and perceptions of risks and benefits on the acceptance of gene technology. Risk Analysis, 20(2), 195-204. https://doi.org/10.1111/0272-4332.202020

Slovic, P. (1987). Perception of Risk. Science, 236, 280-285. https://doi.org/10.1126/science.3563507

Slovic, P. (1993). Perceived risk, trust, and democracy. Risk Analysis, 13(6), 675-682. https://doi.org/10.1111/j.1539-6924.1993.tb01329.x

Smith, F. B. (2006). Consumer Interest and Concern about Genetically Modified Foods: Global Perspectives. Competitive Enterprise Institute. Retrieved from www.cei.org/pdf/5418.pdf

Smith, M. (2000, January 10). Brussels set to unveil food safety authority. Financial Times.

Tait, and Levidow. (1992). Proactive and reactive approaches to risk regulation: The case of biotechnology. Futures, 24(3), 219-231. https://doi.org/10.1016/0016-3287(92)90032-B

Tait, J. (2001). More faust than frankenstein: The European debate about the precautionary principle and risk regulation for genetically modified crops. Journal of Risk Research, 4(2), 175-189. https://doi.org/10.1080/13669870010027640

Tait, J. (Ed.). (2008). Risk Governance of Genetically Modified Crops: European and American Perspectives. In 
O. Renn, \& K. D. Walker (Eds.), Global risk governance: Concept and practices Using the IRGC Framework (pp. 132-153). Springer, The Netherland.

Tait, R. (2008). Risk governance of Genetically Modified Crops- European and American Perspectives. In O. Renn, \& K. D. Walker (Eds.), Global risk governance: Concept and practices Using the IRGC Framework (International Risk Governance Council Bookseries, 1). Dordrecht: Springer.

Tenbült, P., de Vries, N. K., Dreezens, E., \& Martijn, C. (2005). Perceived naturalness and acceptance of genetically modified food. Appetite, 45(1), 47-50. https://doi.org/10.1016/j.appet.2005.03.004

Teng, P. (n. d.). Risk communication: Communication on GMO topics under challenging conditions. Biosafety, 9(2), 47-63.

Timar, L. (n. d.). Consumer views on Genetically Modified Crops. Retrieved from www.business.uni.edu/web/pages/departments/PDFs/Timar.pdf

USDA Advisory Committee on Biotechnology and 21st Century Agriculture. (2006, July 13). Opportunities and Challenges in Agricultural Biotechnology: The Decade Ahead.

Vogt, D. (1999). Food biotechnology in the United States: Science, regulations, and issues. Congressional Research Service Report for Congress.

Zimmerman, R. (1986). The management of risk. In V. T. Covello, J. Menkes, \& J. Munpower (Eds.), Risk evaluation and management (pp. 435-460). New York: Plenum. https://doi.org/10.1007/978-1-4613-2103-3_18

\section{Copyrights}

Copyright for this article is retained by the author(s), with first publication rights granted to the journal.

This is an open-access article distributed under the terms and conditions of the Creative Commons Attribution license (http://creativecommons.org/licenses/by/4.0/). 